DESIGN E INTERAÇÃO SOCIAL

Design de Interação

e Design Universal 


\section{SOBRE OS AUTORES}

Aline da Silva Oliveira Neves | linebelar@gmail.com

Lattes: http://lattes.cnpq.br/3696434843618313

Possui graduação em Design Gráfico pela Faculdade Maurício de Nassau (2014). Possui curso de especialização lato sensu em Artes pela Faculdade Internacional Signorelli do Rio de Janeiro (2015). Atualmente cursa o mestrado em Design da UFPE. A sua pesquisa versa sobre os aspectos do Design Gráfico e da Ergonomia Informacional no Ambiente virtual: Prosimulador, um estudo de caso.

Rowan Henrique Sarmento Silveira | rowansarmento@gmail.com

Lattes: http://lattes.cnpq.br/4690759478912913

Mestrando em Design com ênfase em Artefatos Digitais, pela Universidade Federal de Pernambuco (UFPE), graduado em Comunicação Social com habilitação em Publicidade e Propaganda pela Universidade Federal do Rio Grande do Norte em uma graduação-sanduíche pelo período de um ano, em Ciência de Computação, pela University of Victoria (Canadá). Possui conhecimentos e experiência nas áreas de concepção e desenvolvimento de jogos digitais, no design de interfaces digitais para aplicativos web-based e em conteúdos voltados à interação humano-computador. Interesses de atuação direcionados ao desenvolvimento de artefatos interativos digitais, com especial interesse nas mecânicas e estéticas de jogos digitais.

Danilo Fernandes Vitorino | danilodmster@gmail.com

Lattes: http://lattes.cnpq.br/1422825121043782

Mestrando em Design na linha de pesquisa Ergonomia e Usabilidade de Produtos, Sistemas e Produção pela Universidade Federal de Pernambuco. Bacharel em Design com habilitação em Projeto de Produto pela Universidade Federal de Campina Grande-PB em 2013. Integrante do ErgoLabTE - Laboratório de Ergonomia e Tecnologias Emergentes - UFPE. Atualmente pesquisa sobre interfaces gestuais para a manipulação de softwares de modelagem 3D com foco na Ergonomia e Usabilidade, e utiliza a termografia por infravermelho como ferramenta auxiliar para complementar os métodos tradicionais de análise ergonômica e de usabilidade. 


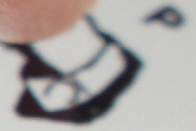

\title{
Design de interação: além do alcance individual
}

\author{
Interaction design: in addition to the \\ individual application
}

Aline Neves, Rowan Sarmento, Danilo Vitorino

\section{Resumo}

O design de interação é uma subárea do design que tem procurado reduzir os aspectos negativos da experiência das pessoas ao utilizar um produto e ao mesmo tempo melhorar seus aspectos positivos (ROGERS et al., 2013). 0 presente estudo almeja apresentar os conceitos, aplicações e o apoio do design universal para evidenciar como o design de interação pode contribuir para uma abrangência igualitária, em que pessoas com diferentes perfis e limitações podem utilizar o mesmo artefato, tendo uma boa experiência de uso. Trataremos o conceito de inovação social e inclusão no mundo digital e apresentaremos algumas aplicações práticas na área de interação humano-computador como softwares e games.

Palavras-chave: Interação; Inovação Social; Design Universal.

\section{Abstract}

Interaction design is a design of the subarea that has sought to reduce the negative aspects of the experience of people using a product and at the same time improving its positive aspects (Rogers, 2013). This study aims to present the concepts, applications and support of universal design to show how interaction design can contribute to an equal extent, where people with different profiles and limitations can use the same device, with a good user experience. We will address the concept of social innovation and inclusion in the digital world and present some practical applications in the field of Human-Computer Interaction as software and games.

Keywords: Interaction; Social Innovation; Universal Design. 


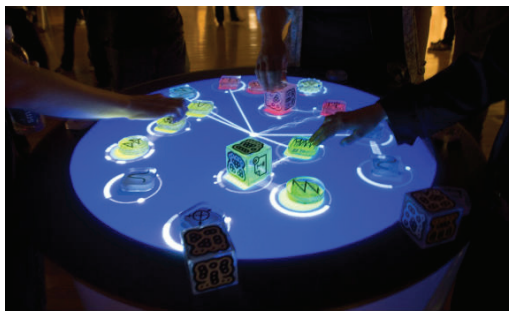

Fonte: SmartMundo.com.

\section{INTRODUÇÃO}

Diversos produtos interativos fazem parte de nosso dia a dia. Se observarmos o que utilizamos diariamente, podemos citar: computador, controle remoto, telefone celular, cafeteira, sanduicheira, relógio... A lista é imensa. Porém, se pensarmos em usabilidade por um minuto, quais deles são verdadeiramente agradáveis e fáceis de usar? Neste momento a lista se torna menor. Certamente, é fácil lembrar-se de algum momento em que já se teve dificuldade para usar algum deles. Produtos que precisam de interação de usuários para a realização de tarefas (por exemplo: sites de compras, caixas eletrônicos, câmeras profissionais) não foram necessariamente projetados com o usuário final em mente; foram apenas projetados para realizar determinadas funções. Na maioria das vezes, são levados em consideração apenas aspectos da engenharia considerados eficazes e, em consequência disso, o usuário final é prejudicado.

0 design de interação preocupa-se com o redirecionamento de questionamentos, trazendo a usabilidade para o processo, desenvolvendo produtos interativos que sejam fáceis, eficazes e agradáveis de utilizar, pensando sempre na perspectiva do usuário. Winograd (1997, p. 160) descreve o design de interação de forma mais geral: "o projeto de espaços para comunicação e interação humana". Thackara (2001, p. 4) observa "o porquê e o como de nossas interações cotidianas usando computadores". Saffer (2010, p. 4) destaca "a arte de facilitar as interações entre os seres humanos por meio de produtos e serviços.." Em suma, o objetivo principal do design de interação está em criar experiência com o usuário na interação com produtos.

Uma boa interação do usuário com o sistema é um objetivo perseguido por projetos de design de interface, sendo uma necessidade reconhecida e divulgada. Esse objetivo vem, ao longo do tempo, ampliando-se e tornando-se cada vez mais complexo, no mesmo ritmo em que os produtos com interfaces digitais tornam-se mais populares e atendem a cada vez mais necessidades.

\section{DESIGN DE INTERAÇÃO E DESIGN UNIVERSAL}

Rogers et al. (2013, p. 8) definem design de interação como: "Projetar produtos interativos para apoiar o modo como as pessoas se comunicam 
e interagem em seus cotidianos, seja em casa ou no trabalho", e complementam, acerca de sua finalidade: "Uma preocupação crucial do design de interação é desenvolver produtos interativos que sejam usáveis, o que genericamente significa produtos que sejam fáceis de aprender a usar, eficazes e que proporcionem ao usuário uma experiência agradável" (ROGERS et al., 2013, p. 2).

Verificamos que é o segmento do design que lida com o projeto da interação do homem com algum tipo de artefato, podendo ser um dispositivo digital ou analógico, como televisão, calculadora, máquina de café, caixa eletrônico, website, software, aplicativo móvel etc. Podemos conferir que boa parte dos dispositivos interativos existentes são mistos, isto é, reúnem interface física e digital em um único produto, e muitas vezes uma depende da outra para funcionar.

Segundo Rogers et al. (2013), os princípios de design utilizados no design de interação são: visibilidade, feedback, ${ }^{1}$ restrições, consistência, affordance, ${ }^{2}$ entre outros, destinados a orientar os designers no projeto de interfaces. Os autores afirmam que as atividades básicas para o processo de design de interação são:

- identificar necessidades e estabelecer requisitos, buscando conhecer os usuários-alvo e levantando dados sobre suas necessidades;

- desenvolver designs que vão ao encontro desses requisitos, com ideias que atendam aos requisitos e a produção de um modelo conceitual para o produto;

- construir versões interativas de maneira que possam ser transmitidas aos outros e apreciadas;

- avaliá-las, medir sua aceitabilidade e usabilidade.

Rogers et al. (2013) consideram a disciplina como a peça fundamental para todas as outras que se preocupam com a pesquisa e o projeto de sistemas computacionais. Desse modo, é a interseção ou ponto central entre as mais variadas áreas do conhecimento que contribuem no processo de desenvolvimento da interação.

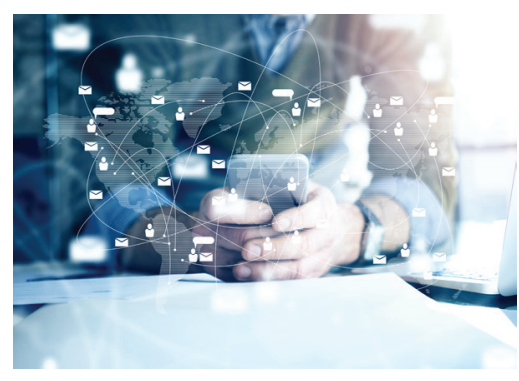

\footnotetext{
10 devido retorno das ações auxilia o usuário a continuar a tarefa, podendo a resposta ser verbal elou visual ou de áudio.

${ }^{2}$ Quando o objeto é autoexplicável, quando a forma de interação é evidente.
} 
Possibilidade e condição de alcance para utilização, com segurança e autonomia, de espaços, mobiliários, equipamentos urbanos, edificações, transportes, informação e comunicação, bem como de outros serviços e instalações abertos ao público, de uso público ou privados de uso coletivo, tanto na zona urbana como na rural, por pessoa com deficiência ou com mobilidade reduzida. (BRASIL, 2015)

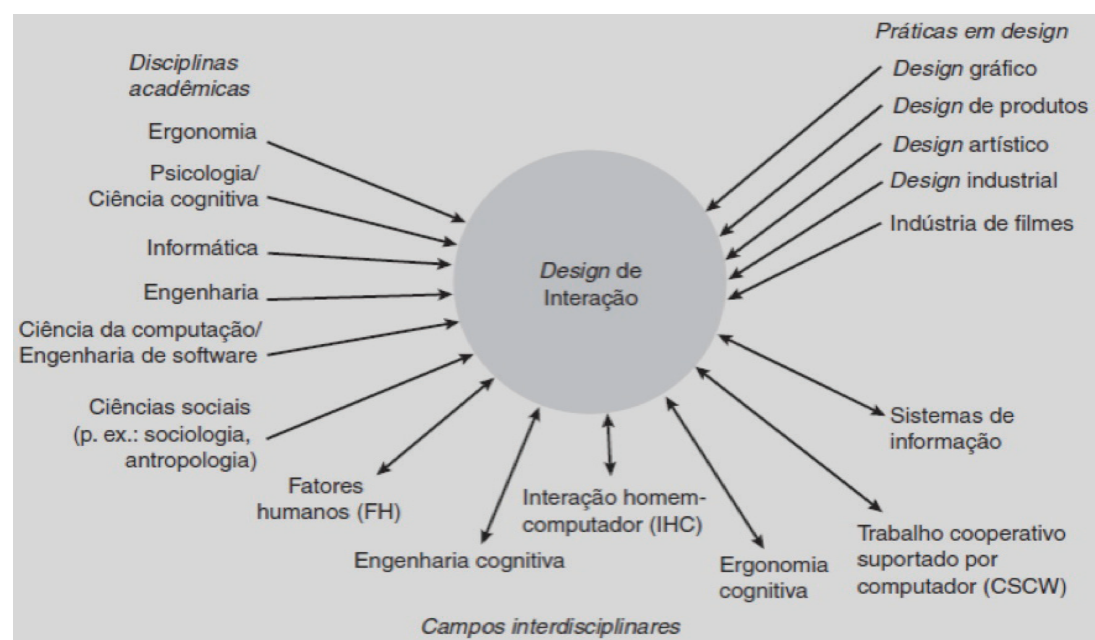

O design de interação como peça fundamental para a pesquisa e projeto de sistemas computacionais. Fonte: Rogers et al. (2013).

Uma preocupação bastante pertinente no design de interação é o grau em que o produto interativo é acessível para o maior número de pessoas possiveis (ROGERS et al., 2013), denominado em normas e leis como "acessibilidade" - cujo foco principal está nas pessoas com algum tipo de limitação física, sensorial ou motora. Nascimento (2015) define acessibilidade de forma simplificada como: "Ausência de barreiras que garante a igualdade de oportunidades". De forma aprofundada, a Lei ${ }^{\circ}$ 13.146, de julho de 2015, a determina como:

Com relação à definição de deficiência, segundo a NBR9050, trata-se de "Redução, limitação ou inexistência das condições de percepção das características do ambiente ou de mobilidade e de utilização de edificações, espaço, mobiliário, equipamento urbano e elementos, em caráter temporário ou permanente" (ABNT, 2004).

No entanto, Rogers et al. (2013) informam ser trivial as pessoas utilizarem o tema de acessibilidade no design de interação e explorá-lo em termos de algumas deficiências física específicas, como a limitação visual e a dificuldade de locomoção. Existe uma ampla variedade de usuários, incluindo idosos, pessoas com daltonismo, obesidade, dislexia, membros curtos ou ausentes, traumas psicológicos, Parkinson, entre outros. É evidente que tratar de todas essas particularidades é praticamente impossível, mas buscar soluções para essas variedades de pessoas é mais uma oportunidade de o design 
contribuir com a sociedade, e as soluções muitas vezes podem facilitar a vida de usuários comuns sem limitações evidentes. Os sistemas computacionais (softwares de computador, aplicativos móveis, games) são bastante flexíveis e podem ser adequados facilmente, sem os custos altos de produtos físicos ajustáveis, como os meios de transporte (carro, ônibus, avião etc.) que necessitam de investimentos altíssimos e muitas vezes não atendem as expectativas de uma ampla variedade de necessidades.

Desse modo, lançamos mão do design universal, que pode contribuir com o design de interação por meio de seus princípios fundamentais para o desenvolvimento de artefatos interativos com uma maior abrangência da população. 0 Centro de Desenho Universal (CUD, 2016), da Universidade da Carolina do Norte, define design universal como "design de produtos e ambientes a serem utilizados por todas as pessoas, na maior medida possível, sem a necessidade de adaptação ou desenho especializado". 0 decreto N 5.296/04, de 02 de dezembro de 2004, define-o como:

O CUD (2016) desenvolveu sete princípios do design universal em 1997, tendo como objetivo apoiar a concepção de produtos e ambientes para que eles fossem utilizáveis, sem a necessidade de adaptação, para a maior quantidade de pessoas possível. Os princípios são:

1. Uso equitativo: o design é útil e comercializável às pessoas com diversas habilidades.

2. Flexibilidade de uso: o design acomoda uma ampla gama de preferências e habilidades individuais.

3. Uso simples e intuitivo: uso do design de fácil compreensão, independentemente da experiência, conhecimentos, competências linguísticas ou nível de concentração atual do usuário.

4. Informação perceptível: o design comunica eficazmente a informação necessária para o usuário, independentemente de suas condições ambientais ou habilidades sensoriais.

5. Tolerância ao erro: o design minimiza perigos e as consequências adversas de ações acidentais ou não intencionais.

6. Baixo esforço físico: o projeto pode ser usado de forma eficiente, confortável e com o mínimo de fadiga.
Concepção de espaços, artefatos e produtos que visam atender simultaneamente todas as pessoas, com diferentes caracteristicas antropométricas e sensoriais, de forma autônoma, segura e confortável, constituindo-se nos elementos ou soluções que compõem a acessibilidade. (BRASIL, 2004) 
7. Tamanho e espaço para aproximação de uso: um tamanho e espaço apropriados são fornecidos para aproximação, alcance, manipulação e utilização, independentemente do tamanho do corpo, postura e mobilidade do usuário.

Desse modo, o design de interação, por meio da sua multidisciplinaridade, pode fazer uso dos princípios do design universal para propor soluções em seus artefatos interativos a fim de que possa diminuir as barreiras e ampliar o alcance para os mais variados tipos de usuários, em prol de um design mais democrático e acessível. Vale salientar que todas as pessoas têm algum tipo de limitação, algumas mais, outras menos, seja físico, mental, motor, de conhecimento, entre outros.

\section{INOVAÇÃO SOCIAL E INCLUSÃO NO MUNDO DIGITAL}

A inovação social consiste em uma mudança na maneira de fazer as coisas, um elemento inovador dentro de um contexto. Ela representa uma descontinuidade com relação às soluções sempre oferecidas e propõe uma resposta criativa a problemas econômico-sociais, não satisfeitos nem pelo mercado nem pelo Estado. Portanto, contribui para o bem-estar das pessoas e das comunidades.

Na sociedade, o suporte tecnológico envolve uma gama muito grande de meios de comunicação que cobre países inteiros, interligando-os aos continentes, e chega até a sociedade. No Brasil, conforme Baggio (2005), a distância entre providos e desprovidos de tecnologia digital contribui muito para o aumento da desigualdade, numa época de fortes inovações na área tecnológica. A inclusão digital da população mais carente permite uma nova perspectiva de vida. Ações que possibilitem a referida inclusão contribuem diretamente para o bem das pessoas.

Diante de mudanças sociais devido aos avanços tecnológicos, criar uma política firme de inclusão digital que contribua para o desenvolvimento do conhecimento é fator determinante para o crescimento econômico, político e social do país e para a promoção de uma inclusão social justa e equilibrada.

Existe um abismo entre ricos e pobres chamado de exclusão digital. Significa dizer que essa é mais uma dificuldade na ascensão social 
para aqueles que não tiveram a oportunidade de uma boa educação. A referida exclusão digital impede as pessoas de terem acesso a uma das principais ferramentas da revolução tecnológica, às tecnologias de informação e de comunicação.

Artigos como o de Bodker (2006) mostram que os pesquisadores reconhecem tanto a mudança do foco de uso da tecnologia do ambiente profissional para o ambiente particular quanto a forte necessidade de tomar medidas para que a situação dos já desfavorecidos não se deteriore ainda mais.

Num contexto de multiplicidade cultural e de competências, o tratamento desse contexto é fator determinante para o modo como queremos ver o uso dessa tecnologia em benefício de nossa sociedade como um todo nos próximos anos.

Variáveis relacionadas ao ambiente social e econômico, ao papel do Estado e à representação social do significado de bem-estar social, entre outras, são tão relevantes quanto o acesso às tecnologias da informação e da comunicação. 0 acesso à informação é uma importante oportunidade de aprendizado, poder e interação, mas pode ser também fonte de desintegração, exclusão social e pobreza, quando esse acesso não se dá de forma uniforme.

Mattelart (2002) afirma que se criou uma "marginalização informacional": a divisão entre ricos e pobres de informação. A sociedade busca amenizar essa divisão por meio de várias ações que vêm sendo chamadas de inclusão social e digital.

Martini (2005) afirma que a inclusão digital objetiva tão somente o uso livre da tecnologia da informação como forma de ampliar a cidadania e combater a pobreza, além da inserção na sociedade da informação e o fortalecimento do desenvolvimento local.

Diante disso, será que inclusão social e inclusão digital estão interligadas com relação a seus propósitos, metodologias e grupos sociais a quem destinam suas ações? Será que a inclusão digital é um caminho para a inclusão social? 


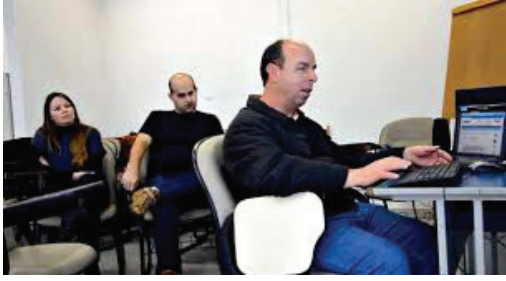

Professor Daniel Ribas: deficiência visual e inclusão digital. Fonte: Acervo pessoal.
No longo prazo, e se ela verdadeiramente for desenvolvida por movimentos sociais poderosos, a inovação social, por seu questionamento aos modos de ação, pela implementação de estratégias diversificadas e pela autonomia das pessoas, pode chegar a ser uma fonte de transformação social e uma impulsora da mudança.

O mercado para a tecnologia assistiva tem um enorme potencial econômico no Brasil. Segundo dados do IBGE de 2015, as pessoas com deficiência física representam $24 \%$ da população. A Associação Brasileira das Indústrias e Revendedoras de Produtos e Serviços para Pessoas com Deficiência estima que as empresas da área faturem mais de 5 bilhões de reais ao ano, com um crescimento anual entre $15 \%$ e $20 \%$.

Com a realização das Paraolimpíadas em 2016 - que aconteceram logo após as Olimpíadas no Rio de Janeiro - as ocasiões de negócio foram ainda maiores. Em uma economia estancada, a inovação tecnológica na área tem muito a contribuir para o desenvolvimento econômico do país. Os pesquisadores, no entanto, deixam claro que, quando se fala em tecnologia assistiva, não é só a inovação tecnológica que importa. Cada avanço na área é importante por contribuir com inovação social no país.

Um excelente exemplo de como a inovação social pode promover a inclusão digital é a história do hoje professor Daniel Ribas, que possui deficiência visual e, quando criança, foi alfabetizado em braile num colégio especializado para cegos. Com seu avanço nos estudos, sua mãe decidiu encaminhá-lo para a escola frequentada pelo irmão, onde poderia aprender os mesmos conteúdos que outras crianças. Como a escola não aceitava alunos cegos, o jeito que o menino encontrou foi tentar enganar os professores, o que durou três dias. Como o conteúdo era todo passado na lousa, ele não conseguia acompanhar as aulas. A escola percebeu e o expulsou. Não havia nenhuma ferramenta que auxiliasse a assimilação das aulas por alunos deficientes. Mesmo assim, Ribas nunca desistiu de estudar. Conseguiu chegar à faculdade, onde cursou Letras. Para chegar ao final do curso, contou com a ajuda de colegas e professores. Hoje, Ribas é professor em uma escola da rede estadual na cidade de Piracicaba, no interior de São Paulo. No começo do ano passado, decidiu voltar a estudar e ingressou na especialização em Educação Especial na área de Deficiência Visual, ofertada pelo Núcleo de Ensino a Distância (NEaD) da Unesp. 
O curso, ofertado pela internet, leva em conta os paradigmas da acessibilidade e é pensado e construído para os alunos com deficiência visual. O conteúdo escrito pode ser "lido" por softwares leitores de tela, as imagens contam com recursos de audiodescrição e toda a navegação acontece via teclado. Ribas afirma que, pela primeira vez, estudou com completa autonomia e independência. "Hoje, ser deficiente visual não é mais estar desinformado. Podemos ter as mesmas informações que aqueles que enxergam", diz o professor.

O curso faz parte de uma iniciativa do NEaD de fornecer cursos a distância ou semipresenciais de forma acessível às pessoas surdas, cegas ou com baixa visão. Esse é um dos principais projetos da Unesp em termos de tecnologia assistiva.

O objetivo da tecnologia assistiva é favorecer a inclusão e a funcionalidade, diz Lígia Maria Braccialli, professora do Departamento de Educação Especial da Unesp em Marília. Sua importância é ainda mais significativa quando se observa que a população com deficiência visual ou auditiva muitas vezes não se insere na sociedade pela imensa falta de dispositivos que a favoreça.

\section{APLICAÇÕES}

Dada a natureza imagética que os artefatos digitais tradicionalmente possuem em seu acesso e navegação, perceptível, por exemplo, no histórico advento dos videogames, telas de alta definição e smartphones, é comum que grande parte de seus produtos de natureza universal seja voltada para a inclusão de uma parcela de usuários que enfrentam uma maior dificuldade na visualização de imagens. Dessa forma, é possível deparar-se com alguns bons exemplos de artefatos digitais universais que procuram trazer uma experiência equivalente tanto para o usuário tido como comum, pleno de sentidos, quanto para deficientes visuais em diferentes níveis. Um bom exemplo é o software embutido Siri no sistema operacional iOS, inserido nos smartphones iPhone, da desenvolvedora Apple. Ainda no âmbito dos smartphones, um suporte de grande valia para uma diversa gama de usuários e aplicações é encontrado no jogo BlindSide, também direcionado à universalidade integradora dos deficientes visuais, uma vez que o desenrolar da experiência se dá 
inteiramente sem imagens, tornando mais acessivel um artefato digital em forma de jogo, um nicho tradicionalmente rico em imagens.

As análises dos dois casos apresentados têm o intuito de verificar como se dá a universalidade de seu acesso, voltando-se a elementos de sua arquitetura de interface, no sentido de expor diferentes artifícios utilizados pelos seus respectivos desenvolvedores; portanto, não necessariamente expondo de forma definitiva aspectos subjetivos de uso. Para isso, na percepção da arquitetura da interface desses softwares voltados a um acesso universalizado, foram utilizados elementos de estudo de caso na sua investigação. Segundo Yin (2002, p. 20), o estudo de caso é "uma estratégia que envolve investigação aprofundada de eventos ou instâncias isolados em contexto, usando múltiplas fontes de pesquisa e evidência" (tradução livre). 0 estudo de caso, dessa forma, como afirmam Hanington e Martin (2012), foca na obtenção de conhecimento específico sobre esses eventos ou instâncias, sendo útil em pesquisa exploratória no intuito de comparação, informação e inspiração, bem como no estudo de efeitos de mudanças, novas programações ou inovações, como é o caso dos objetos de análise aqui trazidos, que procuram trazer um diferencial de universalidade de acesso em suas interfaces. Embora a prática completa de estudo de caso pode exigir níveis abrangentes de informação, esse não é o caso aqui, uma vez que o foco da investigação se apresenta de forma bastante específica e estrutural. Dessa forma, valendo-se dos preceitos do estudo de caso e inspirando-se no modelo de análise de jogos digitais do MIT OpenCourseWare (2011), seguem-se algumas etapas para as análises, respectivamente: testar o software extensivamente; definir o tipo de análise (estudo de caso); contextualizar o objeto analisado; trazer uma visão geral de seu funcionamento e elementos formais; concluir a análise. Dessa maneira, uma vez contextualizado e testado extensivamente na busca por revelar aspectos de sua interface, tais aspectos são expostos e confrontados com outros de acesso universal. As análises se encontram nos subtópicos seguintes.

\section{1 Jogo BlindSide}

BlindSide é um jogo eletrônico disponível para computador e smartphones, nas plataformas Mac OS X, PC e iOS. Com sua narrativa situada num universo distópico em que toda a população mundial se torna cega 
literalmente da noite para o dia, o jogador assume o papel do personagem Case e, sem a utilização de recursos visuais, deve escapar de monstros que estão à espreita. Uma vez que se controla um personagem cego, a navegação no universo do jogo se dá guiada somente por sons, e o usuário utiliza-se dos controles de setas direcionais do computador e do giroscópio (sensor de movimento) do smartphone ou tablet. Desse modo, ao se jogar em um computador, a movimentação do personagem se dá apenas pressionando as tradicionais teclas de setas direcionais (nas direções esquerda, cima, baixo e direita), tal qual um jogo de videogame com câmera em primeira pessoa, com a diferença de que nada é exibido em forma de imagem. No smartphone ou no tablet, o controle se dá ao mover o aparelho para a direção em que se deseja ir, ao mesmo tempo que pressionando a parte superior da tela para que o personagem avance e a parte inferior para que ele retroceda, o que simula um eixo de movimento em forma de cruz. A própria tela do jogo, quando em execução, exibe uma mensagem que sugere que o jogador feche os olhos, pois "não precisará mais deles" para a experiência de jogo, exibindo um efeito de vidro quebrado, como se a própria tela do celular estivesse quebrada e não tivesse utilidade para a experiência.

A navegação do jogo, portanto, é totalmente marcada por pistas sonoras, partindo desde o próprio personagem jogável (por meio de gritos em um momento de pânico, ou descrições de ambientes familiares, por exemplo) a demais elementos de cenários e sons de sinalização. De modo a agregar veracidade à experiência, os sons foram configurados de forma tal que transparece a sensação de serem emitidos de diferentes formas, a partir de uma tecnologia de som 3D que, fazendo uso de fones de ouvido, separa o som entre as caixas acústicas direita e esquerda, simulando a sensação de distância e direção de determinado som. 0 diferencial desse jogo é o fator inclusivo que proporciona, trazendo sem distinção a experiência de superar os obstáculos tanto por jogadores que enxergam quanto por jogadores completamente cegos, algo realmente pontual no cenário de jogos eletrônicos, extremamente visual e excludente a pessoas com deficiências visuais.

De modo a se certificar de que o jogo em questão realmente se enquadra de forma satisfatória como produto inclusivo e universal, é possivel avaliá-lo por meio das especificações fornecidas pelo Guia Prático para Acessibilidade em Jogos da AbleGamers (BARLET; SPOHN, 2012) para o desenvolvimento de jogos inclusivos e acessíveis, pressupostos para um

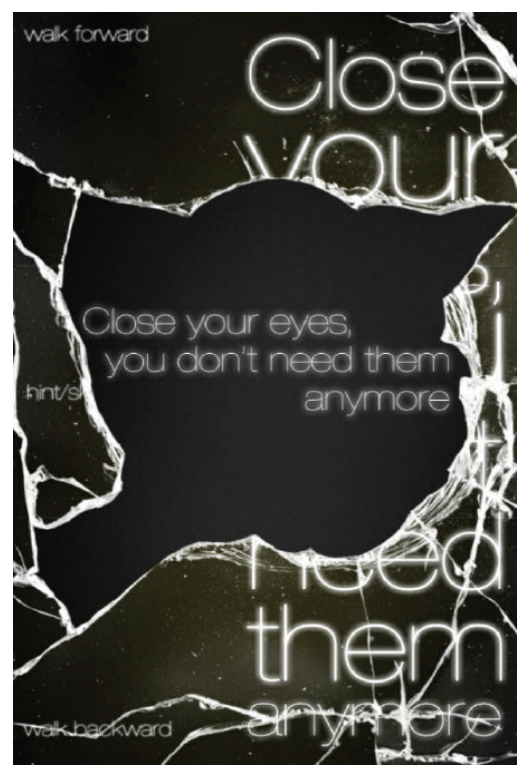

Tela inicial do jogo BlindSide. Fonte: Captura de tela. 
design universal. A AbleGamers é uma organização não governamental norte-americana em defesa de jogadores (gamers) com algum tipo de deficiência, em diferentes níveis. É a maior comunidade e banco de dados de críticas de videogames baseadas na acessibilidade para jogadores com deficiência em escala global, com mais de 3,5 milhões de visitas por mês. A AbleGamers sugere as seguintes especificações de áudio para jogos eletrônicos:

- legendas estão presentes;

- o som do ambiente é incluído;

- identifica o emissor;

- as deixas sonoras são acompanhadas por deixas visuais;

- o jogo pode ser completado com sucesso se ouvir não for nenhuma desvantagem.

Ao se comparar as especificações do BlindSide com as especificações sugeridas pela AbleGamers, percebe-se que duas das especificações são completamente atendidas: "som do ambiente é incluído" e "identifica o emissor". Uma vez que o jogo procura não trazer a maior quantidade possivel de jogadores, mas sim gerar equidade em seu acesso tanto por jogadores completamente cegos quanto por jogadores que enxergam, os dois últimos tópicos não se encaixam em seu perfil, uma vez que interpretam os jogos eletrônicos como uma mídia extremamente visual, de modo que são elementos apresentados principalmente para universalizar (na medida do possível) jogos produzidos para o grande público.

Embora jogos como o BlindSide não sejam uma peça ímpar nem absoluta do design universal, segundo Barlet e Spohn (2012) apresentam-se como uma alternativa para universalizar o acesso aos jogos, pois expandem o alcance do artefato digital a um espectro de jogadores que antes não poderiam desfrutar desse tipo de experiência, com o importante fato de não haver perda de conteúdo ou desvantagens em relação ao jogador pleno de visão. Segundo Preisler (1992), em um estudo controlado realizado em uma creche envolvendo crianças com visão e crianças cegas no intuito de descobrir como se davam suas interações em atividades, foi percebido que crianças cegas raramente tomavam parte na brincadeira das demais crianças, de modo que crianças cegas necessitavam de professores como intérpretes visuais ou como colegas de brincadeira. Esse estudo exemplifica a afirmação de quão socialmente excluídas são as 
pessoas cegas em atividades simples, revelando assim o forte fator social de inclusão que o BlindSide carrega, revelando-se um exemplo simples e bem-sucedido de que é sim possível produzir um conteúdo digital e interativo mais abrangente socialmente.

\subsection{A assistente eletrônica do iOS: Siri}

Ainda no âmbito do smartphone, artefato cada vez mais onipresente e multifacetado no cotidiano social, temos a assistente virtual Siri, desenvolvida pela Apple como uma interface que facilita o acesso por meio de uma forma alternativa de inserção de comandos de usuário. É uma aplicação nativa no sistema operacional iOS, e oferece uma forma alternativa de acesso e execução de determinadas tarefas no aparelho. Por meio de um agente humano artificial, a denominada Siri, simula-se uma conversa com o usuário valendo-se de uma inteligência artificial, de modo a permitir executar diversas funções no dispositivo. A um simples pressionar do botão central do aparelho (o único da parte frontal), é possível ativar a função, que imediatamente passa a captar o áudio falado pelo usuário, seja em forma de comando ou de questionamento. A figura a seguir exemplifica uma tela do próprio aplicativo com algumas sugestões de ações possíveis:

Ao se utilizar de um comando de voz para executar uma dessas ações, é possivel criar uma facilidade e rapidez no acesso de tarefas comuns no aparelho, facilitando o uso não apenas por parte de usuários em condições plenas de utilização, mas também por parte de outros que, de outra forma, teriam dificuldade ou mesmo impossibilidade de utilizá-lo. Uma vez que produz seu output em uma combinação de texto e áudio, o assistente digital é especialmente útil para pessoas com restrições sensoriais, já que o que é falado em áudio também é exibido em texto, uma combinação útil em diversos casos. A imagem a seguir exemplifica o processo de envio de uma mensagem de texto por meio da assistente, no qual o usuário faz sua entrada de informações no dispositivo por meio da fala. Dessa forma, a primeira imagem da sequência exibe a captura do que o usuário falou pelo dispositivo, exposto na forma de texto "Siri, você pode enviar uma mensagem?"; então, o assistente o compreende e pergunta (em texto e áudio) qual o remetente da mensagem. Processos similares aparecem nas outras imagens, como forma de especificação da mensagem.

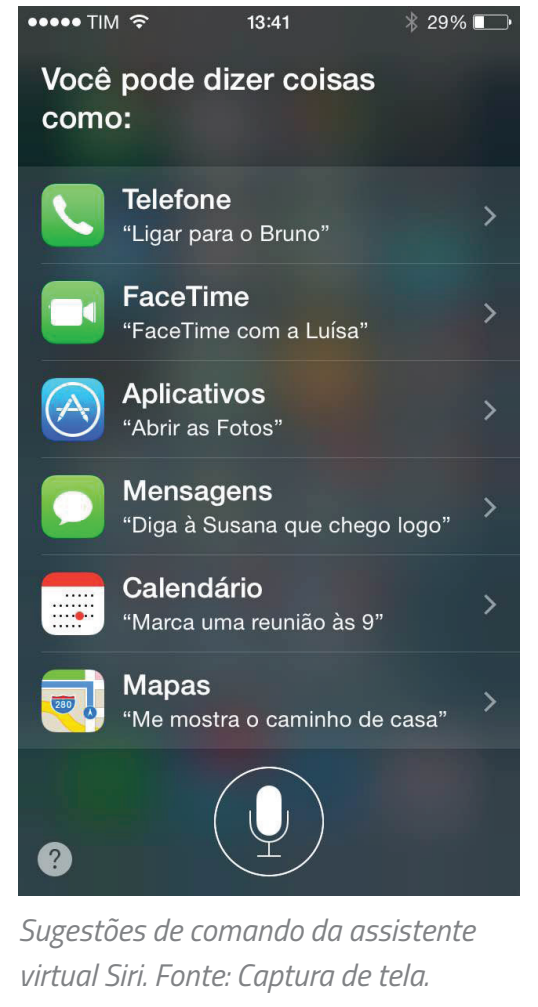

virtual Siri. Fonte: Captura de tela. 

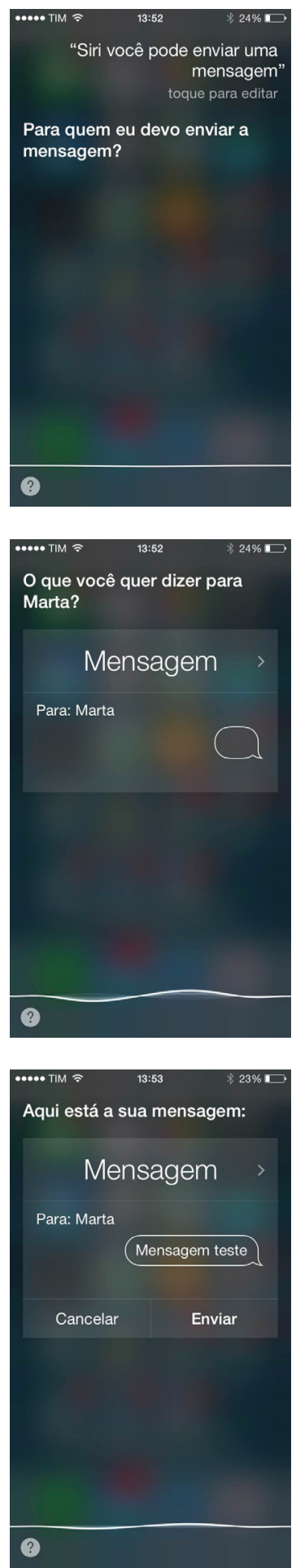

Sequência de tela de envio de mensagem da Siri. Fonte: Captura de tela.
O assistente Siri não possibilita o acesso pleno a todas as aplicações encontradas no aparelho, uma vez que tarefas complexas e muito dependentes da visualidade e de input do usuário não estão em sua área de abrangência, bem como aplicativos desenvolvidos por terceiros, que não necessariamente oferecem suporte. Apesar disso, o assistente se prova útil em importantes tarefas esperadas em um aparelho smartphone, já que possui suporte a diferentes formas de comunicação, seja por telefonema, vídeo ou texto, por meio da fala do usuário, valendo-se inclusive da transcrição do áudio emitido pelo usuário para ser utilizado como texto.

\section{CONCLUSÕES}

Verificando os conceitos gerais das disciplinas apresentadas, percebe-se que convergem para o mesmo fim, ou seja, tornar a interação usuárioproduto mais eficiente, eficaz e democrática. Percebe-se também que a conexão dessas disciplinas (design de interação e design universal) pode contribuir para a inovação social e inclusão no mundo digital, possibilitando que pessoas com diferentes perfis possam interagir com o mesmo produto.

A vantagem é que essa adequação nas interfaces digitais, para atender necessidades diferentes, é mais simples do que em produtos físicos, e o investimento é, na maioria das vezes, mais intelectual do que financeiro, cabendo aos designers de interação solucionarem esses problemas com métodos específicos e com o apoio de outras disciplinas e áreas do conhecimento. Apesar de averiguarmos o crescente desenvolvimento de aplicativos e games direcionados para dar maior acessibilidade aos usuários, é importante salientar que eles não são suficientes e precisam de melhorias, tendo em vista que muitas vezes solucionam apenas necessidades específicas e não atendem o conceito de design universal, o qual exige que a solução atenda o maior número possível de pessoas.

\section{REFERÊNCIAS}

ASSOCIAÇÃO BRASILEIRA DE NORMAS TÉCNICAS. NBR 9050: Acessibilidade a edificações, mobiliário, espaços e equipamentos urbanos. Rio de Janeiro: ABNT, 2004.

BAGGIO, R., Inclusão digital: despreparo e assistencialismo são desafios no Brasil. Disponivel em: <http://oglobo.globo.com/tecnologia/mat/2016/09/14/inclusao_digital>. Acesso em: 11 out. 2016 
BARLET, M.; SPOHN, S. An Alternative to Universal Design. In: Includification: A Practical Guide to Game Acessibility. EUA: The Ablegamers Foundation, 2012.

\author{
Foundation, 2012. \\ Includification: A Practical Guide to Game Acessibility. EUA: The Ablegamers
}

BODKER, S. (2006). When second wave HCl meets third wave challenges. Proceedings of the 4 th nordic conference on human-computer interaction: changing roles, Oslo, p. 1-8, 2006.

BONSIEPE, G. Design: do material ao digital. Florianópolis: Editora Sebrae, 1997.

BRASIL. Decreto N 5.296, de 2 de dezembro de 2004. Regulamenta as Leis nos 10.048, de 8 de novembro de 2000, que dá prioridade de atendimento às pessoas que especifica, e 10.098, de 19 de dezembro de 2000, que estabelece normas gerais e critérios básicos para a promoção da acessibilidade das pessoas portadoras de deficiência ou com mobilidade reduzida, e dá outras providências. Diário Oficial da União, Brasilia, 3 dez. 2004. Disponível em: <http://www.planalto.gov.br/ccivil_03/_ato2004-2006/2004/decreto/d5296.htm>. Acesso em: 30 mar. 2016.

Lei No 13.146, de 6 de julho de 2015. Institui a Lei Brasileira de Inclusão da Pessoa com Deficiência (Estatuto da Pessoa com Deficiência). Diário Oficial da União, Brasilia, 7 jul. 2015. Disponivel em: <http://www.planalto.gov.br/ccivil_03/_Ato2015-2018/2015/Lei/ L13146.htm>. Acesso em: 25 maio 2016.

CENTRO DE POLITICAS SOCIAIS. Mapa da exclusão digital. Rio de Janeiro: FGV, 2003. Disponível em: <http://www.cps.fgv.br/cps/bd/MID/SUMARIO/sumario\%20interativo.htm>. Acesso em: 30 mar. 2017.

CUD - CENTER FOR UNIVERSAL DESIGN. Universal Design. Disponível em: <https://www.ncsu. edu/ncsu/design/cud/>. Acesso em: 26 maio 2016.

CYBIS, W.; BETIOL, A. H.; FAUST, R. Ergonomia e usabilidade. São Paulo: Novatec, 2007.

EPICICLE. The BlindSide. IOS, PC [APLICATIVO] Epicile, 2012.

HANINGTON, B.; MARTIN, B. Universal Methods of Design: 100 Ways to Research Complex Problems, Develop Innovative Ideas, and Design Effective Solutions. Berverly, MA: Rockport Publishers, 2012

IBGE. Censo demográfico 2000. Rio de Janeiro: IBGE. Disponível em <http://www.brasil.gov.br/ economia-e-emprego/2016/09/cresce-numero-de-pessoas-com-deficiencia-no-mercadode-trabalho-formal>. Acesso em: 10 out. 2016.

LÖBACH, B.; VAN CAMP, F. Design industrial: bases para a configuração dos produtos industriais. São Paulo: Edgard Blücher, 2001.

MARTINI, R. Inclusão digital inclusão social. Revista Inclusão Social, Brasilia, IBICT, v. 1, n. 1, 2005. Disponivel em: <http://revista.ibict.br/inclusao/article/view/1501/1685>. Acesso em: 14 set. 2016

MATELLART, A. História da sociedade da informação. São Paulo: Loyola, 2002.

MIT OpenCourseWare. Game Analysis Guidelines. CMS. 300/CMS. 841 Introduction to Game Studies. 2011. Disponivel em: <https:/ocw.mit.edu/courses/comparative-media-studieswriting/cms-300-introduction-to-videogame-studies-fall-2011/assignments/game-analysis/ MITCMS_300F11_GameAnaGu ide.pdf>. Acesso em: 2 nov. 2016.

NASCIMENTO, S. P. Direitos das pessoas com deficiência: conceitos, tendências e desafios Secretaria Nacional de Promoção dos Direitos das Pessoas com Deficiência. $9^{a}$ Reunião Plenária da CNPD Brasilia, 21 de maio de 2015. Disponivel em: <http://www.cnpd.gov.br/wp-content/ uploads/Apresentacao-SDH.pdf>. Acesso em: 26 maio 2016. 
PREISLER, G. M. A Descriptive Study of Blind Children in Nurseries with Sighted Children. In: Anais: Child: care, help and development, n. 19, p. 295-315, 1992.

ROGERS, Y.; SHARP, H.; PREECE, J. Design de interação: além da Interação humano-computador. 3. ed. Porto Alegre: Bookman, 2013. 585 p.

SAFFER, D. Designning for interaction: creating innovative applications and devices. 2. ed. Berkeley: New Ridgers, 2010.

THACKARA, J. In the bubble: designing in a complex world. Cambridge: The MIT Press, 2005.

VERPLANK, B. My PC. In: Designing Interactions. Moggridge, Bill, MIT Press, 2007.

WINOGRAD, T. From computing machinery to interaction design. In: Denning, P; Metcalfe, R. (Eds.). Beyond calculation: the next fifty years of computing. Springer-Verlag, 1997. p. 149-162.

YIN, R. K. Case Study Research: Design and Methods. 3. ed. Thousand Oaks, CA: Sage Publications, 2002. 